\title{
Identidade cultural e globalização em produções artísticas contemporâneas
}

\author{
LURDI BLAUTH \\ GISELE VERARDI JOAQUIM
}

Lurdi Blauth é artista plástica, professora, pesquisadora. Doutora em Artes Visuais, PPGAV, UFRGS/RS, 2005. Doutorado/sanduíche, Université Pantheon-Sorbonne, Paris I, França, 2003. Docente em cursos de graduação, pós graduação em Artes Visuais e mestrado em Processos e Manifestações Culturais; integra o grupo de pesquisa em Linguagens e Manifestações Culturais, Universidade Feevale Novo Hamburgo/RS. Realiza exposições individuais e participa de exposições coletivas, nacionais e internacionais. E-mail: lurdib@feevale.br

Gisele Verardi Joaquim é mestranda no Curso de Pós-Graduação Strictu Senso Mestrado em Processos e Manifestações Culturais, Projeto de Dissertação:Arquivos fotográficos: modificações da cidade no espaço/tempo da memória coletiva e pessoal, Universidade Feevale/RS. Possuiu especialização em Poéticas Visuais, Universidade Feevale, 2011. Atua como professora de Artes em Esteio. Participa de exposições coletivas. E-mail: giseleverardi@yahoo.com.br 


\section{- RESUMO}

O presente estudo aborda alguns aspectos sobre identidade cultural e globalização, a partir das proposições poéticas dos artistas Javier \& Erika, destacando as obras Inforncof e Haciendo Mercado, que foram apresentadas na 8a Bienal do Mercosul, em 2011. Essas obras propõem reflexões críticas sobre a questão da identidade cultural da América Latina do póscolonialismo, apontando as diferenças reais e simbólicas presentes na cultura paraguaia, em oposição às tradições indígenas e práticas capitalistas. $O$ aporte teórico articula o pensamento de Nestor Garcia Canclini sob a perspectiva da globalização em suas esferas política, econômica e cultural, problematizando a ampliação do horizonte local e nacional. Stuart Hall trata a questão da identidade no contexto social e cultural, cujas rápidas mudanças, se não houver adaptação, instauram a crise de identidade pelo descentramento, deslocamento e também a sua fragmentação.

\section{PALAVRAS-CHAVE}

Cultura, identidade cultural, globalização, arte contemporânea.

\section{- ABSTRACT}

The present paper approaches some aspects regarding cultural identity and globalization, out of poetical propositions of the artists Javier \& Erika, emphasizing the works Inforncof e Haciendo Mercado, presented at the Mercosul $8^{\text {th }}$ Biennial, in 2011. Those works propose critic reflexions on the post-colonialism Latin America cultural identity matter, pointing to the real and the symbolic differences present in Paraguayan culture, in opposition to the indigenous traditions and capitalist practices. The theoretical basis articulates the thought of Nestor Garcia Canclini under the globalization perspective, in its political, economical and cultural spheres, questioning the local and national horizon broadening. Stuart Hall discusses the matter of identity in the social and cultural context, whose fast changes, if there is no adaptation, create an identity crisis through its destabilization, displacement and fragmentation.

\section{- KEYWORDS}

Culture, cultural identity, globalization, contemporary art.

\section{Introdução}

Ao abordarmos aspectos que identificam uma determinada cultura é preciso considerar a presença de códigos simbólicos adotados por um grupo determinado local, porém, atualmente, percebemos que, não podem ser desconsideradas, as interferências dos efeitos da globalização sobre as diferentes práticas culturais. Ao mesmo tempo em que, a cultura local preserva e repete os seus hábitos e costumes, o fenômeno da globalização tenta disseminar o consumo de novos produtos a ponto de inseri-los no dia-a-dia das pessoas, tornando-os parte daquela cultura, muitas vezes transformando totalmente o modo de vida de um determinado grupo.

Contudo, as noções sobre cultura são complexas uma vez que, os enfoques se alteram ou são compartilhadas no âmbito dos diferentes universos sociais que envolvem uma pluralidade de manifestações culturais. Em termos gerais, a cultura de uma determinada sociedade envolve diferentes dinâmicas, com suas coerências e contradições, modificando, continuamente, os seus significados internos e externos. Além disso, as noções conceituais de cultura, "supõem relações de poder, desigualdades, contradições, e de que todas as modalidades de transmissão de cultura implicam, 
[...] algum poder de dominação" (RICHTER, 2005, p. 17).

Por outro lado, os conceitos de cultura e globalização se contrapõem, pois enquanto a cultura tenta manter as suas referências identitárias locais, em respeito às tradições e história construída, a globalização tenta universalizá-las, em favor do capitalismo e do consumismo (política e economia). Porém, diante dos aspectos moventes das relações instauradas pela globalização através da promoção e circulação incessante de produtos e das tecnologias de informação, percebemos que essas mudanças provocam a incorporação de novas formas de organização e estruturação socioculturais.

Nessa direção globalizadora de redimensionamento das estruturas sociais, englobam-se diferentes expressões e mesclas culturais que estão presentes em países da América Latina, por exemplo, sendo apontadas por Nestor Garcia Canclini como um labirinto cultural, denominando-as de culturas híbridas. Os acordos de livre-comércio entre a União Europeia, EUA, Canadá, México e os países pertencentes ao Mercosul fomentam o deslocamento entre culturas, abrangendo aspectos socioculturais e econômicos. Além disso, esse "jogo entre desejos e estruturas, as mercadorias e o consumo servem também para ordenar politicamente cada sociedade. $O$ consumo é um processo em que os desejos se transformam em demandas e em atos socialmente regulados" (CANCLINI, 2010, p. 65).

No âmbito dessas diversas mesclas e ordenamentos culturais, podemos entender que a ideia de nação e globalização envolve pessoas, deslocamentos, hibridizações, cujas mudanças culturais ocorrem em escala local-global. Além disso, o acesso as outras culturas é, igualmente, propiciado através de meios midiáticos e eletrônicos como a televisão, a internet, e-mail, o jornal, possibilitando uma "migração virtual”, não sendo mais caracterizadas apenas pelo movimento migratório físico, como era realizado em épocas anteriores.

No contexto atual, a globalização ainda pode ser vista como "horizonte imaginado por sujeitos coletivos e individuais, isto é, por governos e empresas dos países dependentes, por produtores de cinema e televisão, artistas e intelectuais, que desejam inserir seus produtos em mercados mais amplos (CANCLINI, 2007, p. 29). Para este autor, o processo da globalização envolve muitos discursos que inclui fusões, porém nem sempre todas as nações são incluídas. Hoje, vivemos em uma "globalização imaginada", onde se faz necessário distinguir "nos vários processos culturais, o que há de real e o que há de imaginário nessa ampliação do horizonte local e nacional" (Idem, p. 29). Nesse sentido, não se pode negar que as estratégias da globalização estão modulando a sociedade como um todo, pois os intercâmbios estão mais fluidos, as fronteiras se abrem, propiciando, cada vez mais, contatos reais ou virtuais entre as distintas culturas.

Por outro lado, esses deslocamentos oriundos dos efeitos da globalização provocam mudanças estruturais na sociedade, e também refletem sobre as identidades pessoais, e de certa maneira, geram o descentramento do indivíduo "tanto do seu lugar no mundo social e cultural quanto de si mesmos - constitui uma crise de identidade para o indivíduo" (HALL, 2006, p. 9). Nesse processo, contudo, essa "crise de identidade" ocorre diante de experiências vivenciadas entre dúvidas e incertezas em um mundo em constante transformação, sendo, igualmente, percebidas no campo simbólico, em suas diferentes linguagens estéticas.

Nesse estudo, discutimos a influência da globalização sobre a identidade local, através de produções artísticas que problematizam esses aspectos em suas obras. Em 
termos de América Latina, essas questões são abordadas por diversos artistas na contemporaneidade, como podemos detectar em obras que configuram a "criação de cartografias, imaginárias ou ressignificadas, que marcam a poética das migrações, mas, muitas vezes evidenciam a crítica a hierarquias e a centralidades geopolíticas" (CATTANI, 2007, p. 31). A autora ainda comenta que, em relação à América Latina, "somam-se as elaborações críticas de momentos de opressão, quando as hierarquias, as centralidades, as fronteiras, por vezes mesmo a ideia de nação, foram subvertidas em obras que reconfiguram metaforicamente o regime vigente as suas estruturas" (Idem, p. 31).

No campo da arte, percebemos reflexões e posicionamentos críticos em relação à globalização em aspectos que transversalizam as fronteiras locais, o nacional e o global. Nesse contexto, discorremos sobre algumas noções sobre identidade cultural e globalização, destacando dois artistas que vivem em Assunção, Paraguai, como Javier López (Havana, Cuba, 1974) e Erika Meza (São Pedro, Paraguai,1968), os quais trabalham, principalmente, com vídeo e videoperformance. Em suas proposições poéticas, abordam questões relacionadas com a realidade latina pós-colonial e a identidade nacional, em oposição às tradições indígenas e práticas capitalistas oriundas da globalização.

\section{Arte contemporânea: aspectos culturais na identidade latino-americana}

No contexto da arte contemporânea latino-americana percebemos uma significativa produção simbólica de artistas que problematizam questões relacionadas com identidade e dependência cultural, territorialidade e globalização. Nesse cenário, em 1996, foi criada a Bienal de Artes Visuais do Mercosul, em Porto Alegre, RS, que, além oportunizar uma maior visibilidade entre a produção artística de brasileiros e latinos, tem focalizado, em suas diversas edições, exposições com proposições temáticas que discutem aspectos vinculados a identidade e pluralidade, territorialidade, local e lugar, a homogeneização e a globalização, etc. e os seus possíveis cruzamentos. Cabe mencionar, que o projeto curatorial da primeira Bienal do Mercosul, (1997) desdobrou-se em três vertentes (construtiva, política e cartográfica). Na Vertente Cartográfica, por exemplo, os artistas representantes dos diversos países, mostraram questões relacionadas com "suas próprias identidades por meio da cartografia, ou seja, sobre a forma como buscaram produzir uma consciência do lugar e do seu território" (FIDELIS, 2005, p. 57) e também apontar criticamente a questão do eurocentrismo sobre a história da América Latina. O curador Frederico Morais coloca:

[...] é uma reação ao processo de globalização, isto é, a afirmação do território próximo, [...] abrange não apenas a noção [...] de território, geralmente confrontada com a globalização, como, também, aspectos antropológicos, etnográficos e arqueológicos que têm interessado ao artista plástico contemporâneo (Idem, p. 57).

Como podemos detectar, desde a primeira mostra, as proposições curatoriais refletem problemas comuns da arte latino-americana, englobando a sua diversidade de direções e inter-relações estéticas permeadas ao longo da sua história. A 8ª Bienal do Mercosul, que ocorreu em 2011, por exemplo, trouxe à tona, questões relacionadas com delimitações territoriais e políticas dos países que abrangem a América Latina, uma vez que, nem sempre, estão encerradas dentro dos limites que corresponderiam a uma autonomia cultural. Nessa bienal, cuja temática foi "Ensaios de Ge- 
opoética", participaram artistas de 34 países que apresentaram obras relacionadas com a ideia de nação, novas cartografias, as relações entre as condições políticas e geográficas, o regional e o global, as rotas de circulação e o intercâmbio de capital simbólico, a cidadania em territórios não-urbanos, o status político de nações fictícias e a relação entre ciência, viagem e colonização (José Roca, curador-geral, 2011). Para o curador dessa edição, "a 8ª Bienal está inspirada nas tensões entre territórios locais e transnacionais, entre construções políticas e circunstâncias geográficas, nas rotas de circulação e intercâmbio de capital simbólico" (Catálogo Bienal, 2011, p. 12).

A mostra esteve representada, sobretudo, por questionamentos relacionados a localidades e fronteiras reais e simbólicas, e a cultura enquanto uma rede de práticas e relações ativas, não apenas resultado de um consumo passivo. Assim, destacamos duas obras Inforncof, (fotografia) e Haciendo Mercado (vídeo) que estiveram expostas nessa 8a Bienal do Mercosul, da dupla de artistas Javier López \& Erika Meza, os quais abordam de forma crítica a exploração exercida pelas influências e as mudanças desencadeadas pela globalização sobre determinados aspectos da identidade e autonomia cultural.

A obra Inforncof (Figura1), por exemplo, é constituída por uma fotografia, em grande formato, que se apropria de meios visuais utilizados na publicidade, apresentando a imagem de três pessoas, uma criança no primeiro plano, e um homem e uma mulher no segundo plano. Essa imagem exibe uma fotografia de uma família convencional, estando todos vestidos com roupas simples, porém, com características sociais, chamando a atenção pela mesma expressão facial das três pessoas. A princípio, observamos a imagem como uma foto comum, contudo, o fato de terem gravados em suas testas a palavra Inforncof, e as mãos unindo as três pessoas, nos leva a indagar sobre o que esta imagem pretende anunciar e vender. Qual o motivo de ter uma palavra gravada na testa dessas pessoas? Podemos dizer que, num primeiro momento, a palavra ravada. da"'uagemxx primiras aulas da juracyssoas, como se alrtuguo de fama\#imgNav age como uma marca de um anúncio publicitário sobre a imagem dessas pessoas, questionando as suas condições econômicas, sociais e culturais.

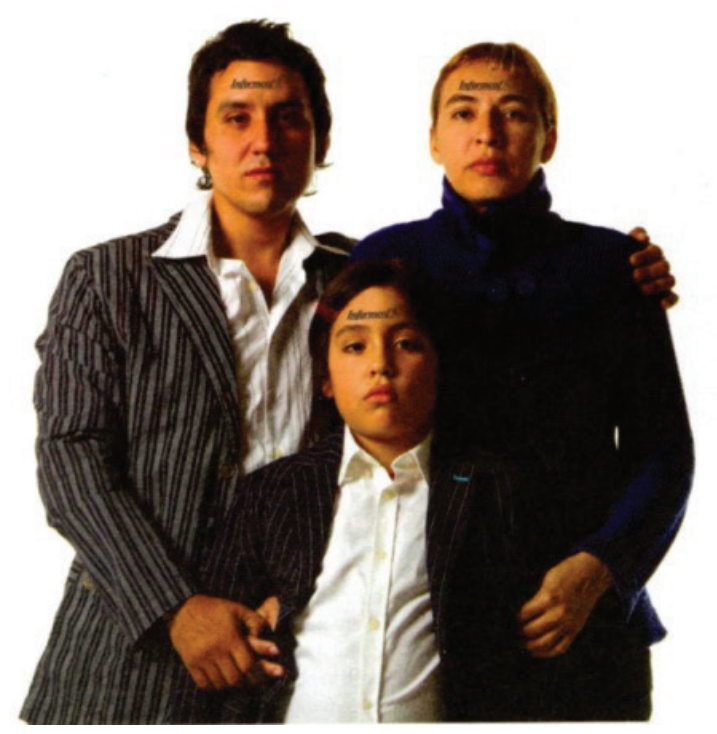

Figura 1 - Javier \& Érika, 2007. Informcof, Memorandum de la multiplicación de fuerzas. Impressão sobre tela vinílica, 300 × $200 \mathrm{~cm}$. 
Ao mesmo tempo, essa obra também procura elencar de forma crítica a relação de compra, venda e consumo de produtos, nem sempre estão aliados às reais necessidades, e que são, muitas vezes, impostos e rotulados. Nessa imagem, o que se impõe é o próprio ser humano enquanto produto rotulado, passível de compra e venda, e de certa maneira, insinuando sobre a questão da homogeneização do indivíduo, a perda de identidade diante do borramento dos limites fronteiriços provenientes do mundo globalizado.

Néstor García Canclini (2007), ao tratar da globalização em suas esferas política, econômica e cultural, aponta para as diferenças entre o que pertence ao real e o que pertence ao imaginário, referindo-se a ampliação do horizonte local e nacional. $O$ autor questiona sobre o fator da uniformização do mundo proveniente das interferências do mercado econômico e como essas novas influências poderiam ser repensadas em termos de arte, cultura e comunicação.

Ao pensarmos no Mercosul, que é um acordo político com a finalidade de criar um livre-comércio nos países latinos, não são questões simples de serem tratadas, assim como também ocorre entre outros países, com negociações e riscos eminentes. Essas novas relações econômicas globalizadas fomentam a necessidade de ampliar mercados que acabam afetando a produção interna de muitos países, e com isso indústrias e, consequentemente, também são extintos os empregos, provocando migrações em massa, conflitos étnicos e regionais. No entendimento de Canclini,

[...] É difícil obter consenso popular para mudanças nas relações de produção, comércio e consumo que tendem a depreciar os vínculos das pessoas com seu território nativo, a suprimir postos de trabalho e a achatar os preços dos produtos locais. O imaginário de um futuro econômico próspero eventualmente suscitado pelos processos de globalização e integração regional é muito frágil se não se leva em conta a unidade ou diversidade de línguas, comportamentos e bens culturais que dão sentido à continuidade das relações sociais (2007, p. 24).

Nesse aspecto, mesmo que as questões identitárias locais sejam frágeis e prejudicadas, as relações interculturais devem ser levadas em conta no processo global, ao mesmo tempo, esse processo permite a "compreensão do que podemos fazer e ser com os outros, de como encarar a heterogeneidade, a diferença e a desigualdade" (Idem, 2007, p. 28). Na medida em que compremos melhor a diversidade das diferenças, o distante torna-se mais próximo, permite-se imaginar uma convivência global menos incompreensiva, do que em períodos de colonização e imperialismo.

Na obra Inforncof percebemos o homem produto, o homem comum e homogeneizado, que não representa mais um povo, uma nação, mas é o produto oriundo de um mercado no qual está inserido. Dessa forma, essa obra problematiza a questão da identidade cultural e as suas transformações em função da inserção numa sociedade globalizada, cujas características fomentam a exploração econômica dos menos favorecidos, dos países pobres, apropriando-se dos seus recursos naturais e culturais, do trabalho, etc.

Diante desse contexto globalizado, como podemos pensar a questão da identidade, uma vez que, ela está diretamente ligada a uma determinada cultura, com a sua maneira peculiar de se diferenciar em relação à classe, gênero, etnia e nacionalidade? Na medida em que os aspectos sociais se modificam rapidamente, a 
concepção de identidade deve, igualmente, adaptar-se, porém, quando isso não ocorre, pode-se afirmar a instauração de uma crise. E qual seria essa crise? Quem são as pessoas nessa obra Inconform? As suas origens culturais ainda podem ser identificadas? Ao observamos os elementos iconográficos dessa obra, quais são as referências para identificar os seus aspectos culturais?

Essas indagações nos levam a pensar sobre a constituição de identidades homogeneizadas (todos vestem da mesma maneira, por exemplo), ao mesmo tempo em que se fragmentam, também são deslocadas e descentradas, diante de uma sociedade bombardeada, simultaneamente, pelas múltiplas informações que ativam constantemente novas necessidades de consumo.

Stuart Hall (2006) reflete sobre as implicações dessas mudanças estruturais que a globalização exerce sobre as identidades modernas e pós-modernas, cujas consequências são difíceis de apontar alguma afirmação conclusiva. O autor salienta, sobretudo, três aspectos em relação às mudanças que ocorreram para compreendermos como a identidade foi se estruturando ao longo dos tempos: o sujeito do Iluminismo, o sujeito sociológico e o sujeito pós-moderno. A concepção de identidade no sujeito do lluminismo, por exemplo, baseia-se no indivíduo que, ao nascer já possui toda a capacidade de razão, consciência e ação e, ao longo de sua vida irá desenvolvê-las permanecendo sempre idêntico a ele mesmo. Ou seja, "o centro essencial do eu era a identidade de uma pessoa" (Idem, 2006, p. 11).

Já o sujeito sociológico, não era autônomo e nem auto-suficiente, era formado na relação com outras pessoas, valores, sentidos e símbolos no mundo em que se encontrava. Na medida em que o sujeito se relacionava e se modificava, também se identificava perante a cultura. O externo fazia-o identificar-se culturalmente, pois havia assimilado significados e valores. A identidade, então, agrega o sujeito à estrutura, o faz pertencer a uma cultura. Já, o sujeito pós-moderno, vem a ser o sujeito, do qual os trabalhos de Javier \& Érika tratam, um sujeito que hoje possui mais de uma identidade "híbrida", muitas vezes, contraditória e mal resolvida. Identidades que se modificam de acordo com "às formas pelas quais somos representados ou interpelados nos sistemas culturais que nos rodeiam" (idem, 2006, p.13).

Contudo, entendemos que, diante do fluxo atual das múltiplas possibilidades de intercâmbio, a sociedade não se configura mais como espaço e território hegemônico, mas como uma estrutura em constante deslocamento e, consequentemente, os sujeitos que nela vivem também. Para Ernest Laclau (1990, p. 40), "esse deslocamento tem características positivas. Ele desarticula as identidades estáveis do passado, mas também abre a possibilidade de novas articulações: a criação de novas identidades, a produção de novos sujeitos". Em outras palavras, no mundo híbrido atual, a fragmentação, as rupturas, o deslocamento e as mudanças podem enriquecer uma cultura, ou ao contrário, desfigurá-la e transformá-la, a ponto dos sujeitos não saberem com o quê se identificar.

O deslocamento, nas reflexões de José Roca (2011), ocorre pela abertura de zonas situadas que expandem o território simbólico que é definido pelo discurso hegemônico. No campo da arte, são inúmeras exposições que vem tratando de temáticas relacionadas com discussões sobre as questões de país, Estado e nação, pois vivemos em um momento de "novas formas de organização que vão além da territorialidade (no caso das comunidades virtuais): a etnia, as crenças religiosas ou políticas, ou a linguagem" (ROCA, 2011, p. 42). 
Nesse sentido, no entendimento de Roca, a noção de país, definido pelo território geográfico e de estado como organização política, e a de nação é compartilhada pela cultura expressa em história, língua e origem étnica comuns, hoje, são construções questionáveis em suas definições convencionais. Ou seja, as relações tornam-se cada vez mais complexas diante da existência de entidades supraterritoriais e transnacionais (muitas vezes criadas por motivações comerciais), caracterizando-se outras formas de definir vínculos humanos não dependentes apenas do território físico. Nesse aspecto,

toda nação é, de certa maneira, uma ficção, posto que a caracteriza como tal, em um sentido ontológico e incontestável, foi definido culturalmente com o fim de dar a um grupo humano uma série de características que lhes permita identificar como conjunto. E por ser uma criação, as características de nação podem ser redefinidas criticamente (ROCA, 2011, p. 42).

Essas características ficcionais propiciam que artistas em suas criações simbólicas, reflitam sobre as possibilidades de indagar e criticar as diferenças entre o global e o local, o centro e a periferia. No vídeo Haciendo Mercado (3:10), Javier \& Erica produzem uma crítica em relação ao uso de formas de persuasão das práticas do mercado capitalista. Neste vídeo é utilizada a imagem de um homem, que representa um típico paraguaio, que se faz passar por um índio guarani, (grupo étnico do Paraguai), ao mesmo tempo, os artistas se apropriam do discurso de um estudioso do marketing, Philip Kotler. O vídeo é conduzido de forma a envolver o espectador na fala do locutor, o qual dá indicações de estratégias de marketing internacional para a venda de produtos e análise do mercado, salientando as suas oportunidades e ameaças (Figura 2).

O locutor, na medida em que fala, gradativamente, é revelado: num primeiro momento, aparece apenas um fragmento do rosto e a boca do locutor, após, a câmera se afasta para mostrar o rosto, que apresenta características de origem indígena, exibindo o enfeite de penas na cabeça e a roupa rasgada. Por último, revela o corpo que mostra a imagem do estereótipo de um índio, com um colar de pen drivers, que é concluído, com uma fala incisiva e, sobretudo, com uma leve expressão irônica.

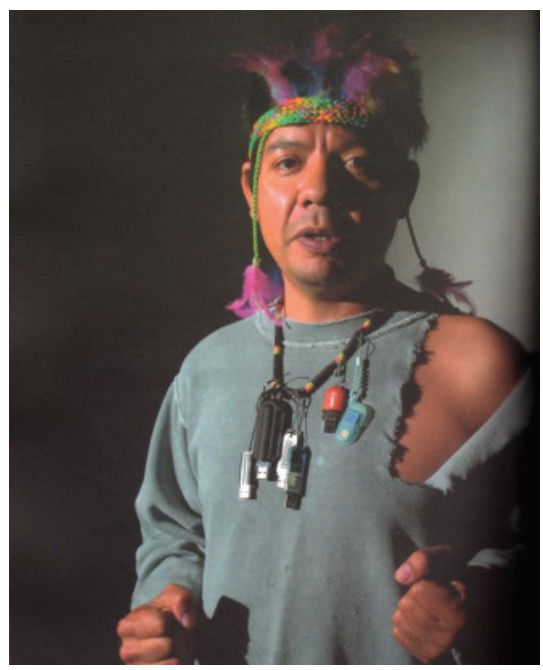

Figura 2 - Javier \& Érika, 2007

Fragmento do vídeo Haciendo Mercado, 3'10". 
Nessa obra, Haciendo Mercado, os artistas tratam da inversão das relações de poder que historicamente oprimiram os índios guaranis, com discursos hegemônicos globais. O vídeo traz à tona, a discussão sobre estratégias utilizadas em um país como o Paraguai, que possui raízes indígenas e um grande déficit econômico e social, e a sua busca pela inserção no mercado global. Problematiza, igualmente, a questão da identidade cultural e linguística de um povo ou de uma região em suas possibilidades de se fortalecer diante do contato com as práticas de mercado capitalistas.

Cabe mencionar que, a Língua Guarani ainda é falada no interior do país por muitos paraguaios, a qual foi quase exterminada pelos colonizadores, risco que ainda corre hoje. No vídeo, muitas palavras pronunciadas, não existem na língua indígena, porém são englobadas e levadas para dentro do Idioma Guarani. Com isso os artistas abrem caminho para uma transformação das atividades econômicas guaranis, procurando desfazer o estereótipo do índio como "bom selvagem" (RAMOS, 2011). Nesse processo, os artistas problematizam as relações de poder, explicitando nessa apropriação do discurso do outro, a possibilidade de modificar nesse jogo de forças, de forma irônica, a inversão simbólica dessas relações.

No entendimento de Ortiz (1994, p. 27) "uma cultura mundializada não implica o aniquilamento das [...] manifestações culturais, ela cohabita e se alimenta delas", neste caso, a língua guarani. Por outro lado, o estereótipo "é uma forma de conhecimento e identificação que vacila entre o que está sempre "no lugar", já conhecido, e algo que deve ser [...] repetido" (BHABHA, 2003, p. 105). Na obra Haciendo Mercado, o estereótipo é acentuado pelo cocar de penas que se contrapõe à vestimenta que está rasgada e remete à nudez do índio, a sua adaptação às roupas, bem como a sua marginalização, e a substituição do colar, que já não é mais feito de ouro, e sim de dispositivos eletrônicos.

Percebemos que, no mundo globalizado, mesmo com as incompatibilidades identitárias, os intercâmbios culturais, as trocas operadas pelas mídias, fazem parte da realidade atual, modificando, inclusive, a imagem que temos sobre os estereótipos. Ou seja, como mencionamos acima, as obras Inforncof e Haciendo Mercado aludem, de forma crítica e irônica, os sistemas instaurados pela cultura globalizada propiciando, talvez, a compreensão dessa realidade com alguma objetividade.

Nessa perspectiva, as inter-relações multiculturais e a industrialização do simbólico desestabilizam a concepção de identidade constituída por núcleos tradicionais e modelos fechados em territórios compactos. Embora, em termos de América-latina persistam a coexistência de ideologias que, de um lado defendem o fundamentalismo, justificando-se em políticas que afirmam as suas diferenças em movimentos étnicos e nacionalistas, por outro lado, a convivência cosmopolita propicia uma maior abertura para a transnacionalização, sublinhando a articulação de uma identidade heterogêneo e multicultural. Para Canclini,

a identidade surge, na atual concepção das ciências sociais, não como uma essência intemporal, mas como uma construção imaginária que se narra. A globalização diminui a importância dos acontecimentos fundadores e dos territórios que sustentavam a ilusão de identidades a-históricas e ensimesmadas (2010, p. 117). 
No momento atual, com a difusão das redes globalizadas, modificaram-se os referenciais convencionais de identidade; são constituídas "em relação com os repertórios textuais e iconográficos gerados pelos meios eletrônicos de comunicação e com a globalização da vida urbana" (Idem, p. 117). Ou seja, mesclam-se distintos códigos e sistemas culturais, isto é, a identidade é multiétnica, e está além das diferenciações constituídas pela produção de signos de uma nação.

Podemos entender que, a identidade cultural é constituída dentro de uma determinada cultura nacional, embora não esteja impressa literalmente nos genes de uma pessoa. Ou seja, de acordo com Stuart Hall, (2006, p. 48) "as identidades nacionais não são coisas com as quais nascemos, mas são transformadas no interior da representação". Por exemplo, sabemos o que significa ser brasileiro, devido a um conjunto de significados que se produzem dentro de um sistema de representação cultural. É da maneira como os indivíduos se reconhecem pertencentes a uma cultura de uma determinada nação, sobretudo, nas relações intersubjetivas instauradas entre determinados grupos sociais, influenciando as suas ações e concepções da própria identidade. Ou seja, são princípios que fundamentam uma unidade nacional, que é construída socialmente, na qual são, igualmente, partilhadas a diversidade e as diferenças que se identificam culturalmente e pertencentes ao mesmo lugar em que vivem.

Contudo, no contexto globalizado, esses princípios de uma cultura nacional unificada são deslocados, interconectam-se novas formas "que atravessam as fronteiras nacionais, integrando e conectando comunidades e organizações em novas combinações de espaço-tempo" (HALL, 2006, p. 67). Em consequência disso, este autor aponta três aspectos provocados pela globalização: primeiro, as identidades nacionais estão se desintegrando devido a essa homogeneização cultural; segundo, as identidades nacionais estão sendo reforçadas para resistirem à globalização; e, terceiro, devido ao declínio das identidades nacionais, uma identidade híbrida está se formando.

Vivemos hoje uma transição que se iniciou quando "as transformações associadas à modernidade libertaram o indivíduo de seus apoios estáveis nas tradições e nas estruturas" (HALL, 2006, p. 25). Talvez até antes, desde o Renascimento até meados do século XX quando as escolas e movimentos artísticos surgiam, e permanecia em atividade por certo período até serem substituídos, uma vez que, os suportes, os questionamentos e objetivos dos artistas era provocar rupturas dos cânones instituídos.

O que percebemos em termos de produção artística, de certa maneira, ainda são mantidos fragmentos de um imaginário de resistência perante a subordinação de todo um mundo, considerando realmente o mundo como todos os continentes, que não vivem mais sem as trocas de capital e trocas simbólicas. Por outro lado, em diversas exposições internacionais, por exemplo, o que ocorre também com a Bienal do Mercosul, as curadorias procuram sinalizar as relações que destacam eixos que transversalizam as fronteiras, desterritorializando as referências nacionais das obras.

Diferente de períodos em que as economias, as comunicações e as artes perfaziam apenas um mercado nacional, "a globalização atua por meio de estruturas institucionais, organismos de toda escala e mercados de bens materiais e simbólicos mais difíceis de identificar e controlar" (CANCLINI, 2007, p. 9). A arte trata dos estranhamentos presentes nesse período, fala daquilo que o global tem de fratura e 
segregação, e, o vídeo citado, por exemplo, expõe metaforicamente a aniquilação do outro.

Acreditamos que, o processo de deslocamento de identidades não seja uma falta de identidade cultural assim como a globalização "imaginada" e a globalização real não seja o extermínio da diferença em valor da homogeneidade política, econômica e cultural. A sociedade e a cultura se refazem a partir do que elas mesmas produzem, valorizam e acreditam, e o indivíduo também. Existem diversas narrativas e visões sobre os efeitos da globalização como, por exemplo, a estagnação econômica e social daqueles que não conseguem se conectar a redes internacionais, permanecem isolados em seu reduto local, gerando, muitas vezes, novas fronteiras de desigualdades. Essas novas possibilidades propiciam uma expansão que oportunizam outros contatos e conhecimentos sobre outras culturas, que não teria sido possível em outras épocas. Para Canclini (2007, p. 137) "as relações transfronteiriças tornaram-se mais decisivas do que a representatividade nacional, e as alianças multiculturais como identificação com uma cultura específica".

Nesse processo, as relações se reconstroem pela hibridização intercultural onde coexiste uma diversidade de sistemas simbólicos. Diante do mundo globalizado, a arte, igualmente, incorpora essas constantes mudanças por meio de distintos processos de criação e procedimentos técnicos que provocam intersecções entre deslocamentos e territórios.

\section{Breves considerações}

Os aspectos culturais que tratam sobre identidade na arte contemporânea da América Latina podem ser observados em obras de diversos artistas que vivem no entorno geográfico do território brasileiro, e que traduzem essas reflexões em suas produções estéticas. A ocorrência das Bienais do Mercosul tem oportunizado uma maior aproximação entre a arte latino-americana, e nesse contato podemos perceber a presença de projetos individuais e coletivos de artistas que buscam problematizar os debates no âmbito social e as condições culturais por meio dos cruzamentos com a arte.

A dupla de artistas Javier e Erika expõem problemas globais a partir do local, da realidade do povo paraguaio. Criticam formas de dominação capitalista, política e cultural desiguais, discriminatórias, alienadoras e pouco democráticas, mostrando a vulnerabilidade do sujeito dentro desse processo. Apresentam, igualmente, de forma irônica, a assimilação da diferença, do outro, que é oportunizada pela abertura à interculturalidade globalizadora, não abandonando a identidade e a origem étnica que pré-definem uma determinada cultura. Portanto, com a globalização configuram-se trocas multiculturais que consolidam alteridades entre universos reais e imaginários em produções estéticas que estão além de apenas interesses políticos e mercantis, propiciando a possibilidade de estarmos em contato com formas de cultura antes nem imaginadas. 


\section{Referências}

BHABHA, Homi K. O local da cultura. Belo Horizonte: Ed. UFMG, 1998.

CANCLINI, Nestor Garcia. Consumidores e cidadãos. Rio de Janeiro: Editora da UFRG, 2010.

A globalização imaginada. São Paulo: lluminuras, 2007.

CATTANI, Iclea. Mestiçagens na arte contemporânea. Porto Alegre, RS: Editora da UFRGS, 2007.

FIDELIS, Gaudêncio. Uma história concisa da Bienal do Mercosul. Porto Alegre, RS: Fundação Bienal do Mercosul, 2005.

Haciendo Mercado. Vídeo. Disponível: http://www.youtube.com/watch?v=HvreoV6s4OQ Acesso em: 21 jul. 2012.

HALL, Stuart. A identidade cultural na pós-modernidade. Rio de Janeiro: DP\&A, 2006.

Javier \& Érika. Disponível: http://universes-in-universe.org/eng./bien/curitiba_biennial/2011/tour/museu_ da_gravura/14_javier_lopez_erika_meza\#imgNav Acesso em: 21 jul. 2012.

LACLAU, Ernest. New reflections on the resolution of our time. Londres: Verso, 1990.

ORTIZ, Renato. Mundialização e cultura. São Paulo: Brasiliense, 1994.

RAMOS, Alexandre Dias (coord.) 8ª Bienal do Mercosul: Ensaios de Geopoética: catálogo. Porto Alegre: Fundação Bienal do Mercosul, 2011.

RICHTER, Ivone Mendes. A interculturalidade e estética do cotidiano no ensino das artes visuais. Campinas: Mercado das Letras, 2003.

ROCA, José. Geopoéticas - Existe um Terceiro Mundo em cada Primeiro Mundo e vice-versa. Porto Alegre, RS: Catálogo Bienal Mercosul: 2011.

SIMÕES, Alessandra. A arte como nação. Disponível: http://www.aica-int.org/spip.php?article1315 Acesso em: 21 jul. 2012. 